\title{
The Near Future of HCV Treatment: Supplementary Treatments against Oxidative Stress will be still useful?
}

\section{Mario Arciello ${ }^{1,2 *}$}

${ }^{1}$ Department of Internal Medicine and Medical Specialties, “Sapienza” University of Rome, Italy

${ }^{2}$ Francesco Balsano Foundation, Rome, Italy

Hepatitis C virus (HCV) is a member of the genus Hepacivirus of Flaviviridae family and its infection is a global health burden because it affects 3- 4 million patients each year while about 150 million peoples are worldwide chronically infected [1], this is due by the fact that more than $80 \%$ of HCV infected patients become chronic [2].

It is a positive single-stranded RNA virus that gives rise to a polyprotein from which have origins: the core protein (core) and the envelope glycoproteins 1 and 2 (E1 and E2, respectively), which are constituents of the HCV particles, $\mathrm{p} 7$ and nonstructural protein 2 (NS2), primarily involved in HCV assembly, NS3, NS4A, NS4B, NS5A and NS5B nonstructural proteins with important roles in the polyprotein processing and HCV replication [3]. HCV infection often causes severe liver diseases, including end stage liver diseases like cirrhosis and HCC [4]. Chronically infected patients are featured by metabolic derangements, inflammation and oxidative stress (OS) [5-7]. The latter, in particular, plays a main role also in metabolic alteration and inflammation. OS occurs when the equilibrium between prooxidant sources and anti-oxidant defenses is unbalanced and the reactive oxygen species (ROS) or reactive nitrogen species (RNS) is not adequately counteracted [8]. The pro-oxidant sources are multiple but, among them, mitochondria have a special place. Mitochondria, that are the power plant of cells, are the main source of ROS production due to aerobic respiration and their high metabolic activity [9]. Unfortunately, they are the also the main targets of reactive molecules that worsening the mitochondrial functionality give rise to a vicious circle able to prompt liver damages. Mitochondria are well known targets of the HCV proteins. They, in fact, interact with these organelles promoting their dysfunctions [10].

Few months ago, after a decade in which pegylated interferon (IFN)- $\alpha$ and ribavirin represented the gold standard in the HCV treatment, new therapeutic approach was approved. Two direct-acting antiviral (DAA) agents known to be NS3/NS4A protease inhibitors, telaprevir and boceprevir [11], are now used in combination with the old therapeutic approach, IFN- $\alpha$ plus ribavirin, the so called triple therapy. Triple therapy reaches a significant improvement of the sustained viral response (SVR) especially in HCV genotype 1 patients (63-75\%) with a reduction in therapy length.

These data, although they are excellent, highlight that in about 30\% of cases triple therapy does not get the desired results, thus supporting the idea that complementary treatments to antiviral therapy, like antioxidants targeted to mitochondria, mitoQ for instance [12], or avoiding mitochondrial dysfunctions, like alisporivir [13,14], could be really useful to HCV treatment. Although, up to now, only in some cases the supplementation of antioxidants have improved the outcome of antiviral treatments when used in combination to IFN [11].

Today the new therapeutic approaches provide DAAs of second generation, targeting also NS5B, and the use of IFN-free therapy, in order to reduce the intolerance to IFN and to expand the number of treatable patients [11].

A combined therapy performed using DAAs of second generation, like Daclatasvir (a HCV NS5A replication complex inhibitor) and Sofosbuvir (a nucleotide analogue HCV NS5B polymerase inhibitor), obtained impressive results in patients affected by HCV genotype 1,2 and 3 with an overall high sustained viral response (SVR) that reach $90 \%$ or more, also in patients in which the previous therapeutic approach failed [15]. In light of these exciting results, some questions arise in my mind, if only less than $10 \%$ of patients are yet resistant to therapy, what will be the future of the studies proposing supplemental treatments against $\mathrm{HCV}$, like antioxidant therapy?

\section{Such approaches are still considered useful and practical?}

The truth is that we cannot know yet. Probably, they may be useful in promoting the reduction of liver damage hence facilitating the response to antiviral therapy in patients more difficult, such as those with advanced fibrosis or cirrhosis [16].

What is certain is that the potential impact of the additional antioxidant therapies may suffer a drastic reduction, and, therefore, all studies aimed at understanding their real clinical impact.

\section{References}

1. Hepatitis C (2014) WHO.

2. Rosen HR, Gretch DR (1999) Hepatitis C virus: Current understanding and prospects for future therapies. Mol Med Today 5: 393-399.

3. Bartenschlager R, Penin F, Lohmann V, André P (2011) Assembly of infectious hepatitis $C$ virus particles. Trends Microbiol 19: 95-103.

4. Farinati F, Cardin R, Bortolami M, Burra P, Russo FP, et al. (2007) Hepatitis C virus: from oxygen free radical stohepato cellular carcinoma. J Viral Hepat 14: 821-829.

5. Arrese M, Riquelme A, Soza A (2010) Insulin resistance, hepatic steatosis and hepatitis $\mathrm{C}:$ A complex relationship with relevant clinical implications. Ann Hepato 19:112-118.

6. Adinolfi LE, Restivo L, Zampino R, Lonardo A, Loria P (2011) Metabolic alterations and chronic hepatitis $\mathrm{C}$ : Treatment strategies. Expert Opin Pharmacother 12: 2215-2234

7. Guo CH, Chen PC, Lin KP, Shih MY, Ko WS (2012) Trace metal imbalance associated with oxidative stress and inflammatory status in anti-hepatitis $C$ virus antibody positive subjects. Environ Toxicol Pharmacol 33: 288-296.

8. Valko M, Rhodes CJ, Moncol J, Izakovic M, Mazur M (2006) Free radicals, metals and antioxidants in oxidative stress-induced cancer. Chem Biol Interact 160: $1-40$.

*Corresponding author: Mario Arciello, Department of Internal Medicine and Medical Specialties, "Sapienza" University of Rome, Via del Policlinico 155 00161, Rome, Italy, Tel: +39-06-49970894; Fax: +39-06-49970947; E-mail: mario.arciello@uniroma1.it

Received February 24, 2014; Accepted February 25, 2014; Published March 02,2014

Citation: Arciello M (2014) The Near Future of HCV Treatment: Supplementary Treatments against Oxidative Stress will be still useful? J Biomol Res Ther 3: e131. doi: 10.4172/2167-7956.1000e131

Copyright: ( 2014 Arciello M. This is an open-access article distributed under the terms of the Creative Commons Attribution License, which permits unrestricted use, distribution, and reproduction in any medium, provided the original author and source are credited. 
Citation: Arciello M (2014) The Near Future of HCV Treatment: Supplementary Treatments against Oxidative Stress will be still useful? J Biomol Res Ther 3: e131. doi: $10.4172 / 2167-7956.1000 \mathrm{e} 131$

Page 2 of 2

9. Rigoulet M, Yoboue ED, Devin A (2011) Mitochondrial ROS generation and its regulation: Mechanisms involved in $\mathrm{H}(2) \mathrm{O}(2)$ signaling. Anti oxid Redox Signal 14: $459-468$

10. Arciello M, Gori M, Balsano C (2013) Mitochondrial dysfunctions and altered metals homeostasis: new weapons to counteract HCV-related oxidative stress. Oxidative Medicine and Cellular Longevity 10.

11. Pawlotsky JM (2013) Treatment of chronic hepatitis C: current and future. Curr Top Microbiol Immunol 369: 321-342.

12. Gane EJ, Weilert F, Orr DW, Geraldine FK, Michael Gibson, et al. (2010) The mitochondria-targeted anti-oxidant mitoquinone decreases liver damage in a phase II study of hepatitis C patients. Liver International 30: 1019-1026.

13. Crabbe R, Vuagniaux G, Dumont JM, Nicolas-Metral V, Marfurt J, et al. (2009)
An evaluation of the cyclophilin inhibitor Debio 025 and its potential as a treatment for chronic hepatitis C. Expert Opinion on Investigational Drugs 18 211-220.

14. Quarato G, D’Aprile A, Gavillet B, Vuagniaux G, Moradpour D, et al. (2012) The cyclophilin inhibitoral is porivir prevents hepatitis C virus-mediated mitochondrial dysfunction. Hepatology 55: 1333-1343.

15. Sulkowski MS, Gardiner DF, Rodriguez-Torres M, et al. (2014) Daclatasvirpluss of osbuvir for previously treated or untreated chronic HCV infection. N Engl J Med 370: 211-221.

16. Feld JJ (2014) The beginning of the end: What is the future of interfer on therapy for chronic hepatitis C? Antiviral Research S0166-3542 (14) 00039-4. 